\section{Artigos}

Andréa Borghi Moreira

Jacinto

UEA

\title{
Decifrando a Mãe do Jarro: uma construção
do encontro etnográfico \\ Decifrando a Mãe do Jarro: uma construção
do encontro etnográfico
}

"Aprender diz respeito essencialmente aos signos. Os signos são objetos de um aprendizado temporal, não de um saber abstrato. Aprender é, de início, considerar uma matéria, um objeto, um ser, como se emitissem signos a serem decifrados, interpretados

(....) tudo que nos ensina alguma coisa emite signos, todo ato de aprender é uma interpretação de signos ou de hieroglifos" (D eleuze, Proust e os Signos, p. 04)

O desafio a que se propõe o presente artigo é o de tentar representar 'instantes' circunscritos de interação e de pesquisa e transformá-los em conhecimento etnográfico. Parte-se do registro de um breve encontro, ocorrido em 1996, no distrito de Serra das Araras, então município de São Francisco, Noroeste de Minas Gerais. Inicialmente construído em notas de campo, posteriormente tratado como narrativa ${ }^{1}$, o registro aqui reproduzido permite um retorno ao acontecimento que se inspira em reflexões sobre análise de rituais e eventos (Peirano 2000), e no foco sobre relações entre ação e linguagem.

Essa perspectiva será desdobrada em diferentes níveis de análise. Primeiro, coloca-se a tentativa de construir uma análise formal do acontecimento/encontro, buscando-se perceber o seqüenciamento de ações e seus arranjos, um olhar sobre o "inner frame" (Tambiah 1985). Associando-se a esse recorte, há também a consideração da dimensão comunicativa interna ao acontecimento, e da interação entre os sujeitos envolvidos, a qual produz mensagens e significados. Um terceiro nível, presente na análise formal e interna ao encontro, busca relacionar duas dimensões de um dos sujeitos do acontecimento - sua ação e sua fala. O objetivo é

Campos 4:155-170, 2003. o de tentar localizar elementos que permitam análise e interpretação do 'fazer-dizer' 
desse sujeito: como sua ação produz mensagens, construídas por intermédio de diversos níveis de interação, e como sua fala é também ato de fala, trazendo significado e eficácia.

Cabe ressaltar que os vários níveis propostos, informantes do "inner-frame" da análise, não estão apresentados no texto de forma estanque. Igualmente, em um segundo momento, eles serão associados ao "outer-frame", ou seja, o contexto situacional que amplia o instante do encontro. Para tanto, contrastar-se-á o acontecimento, em primeiro, com outro encontro, ocorrido no mesmo contexto regional e sob condições semelhantes; e, posteriormente com elementos fornecidos pela literatura histórico-memorialista do Noroeste de Minas Gerais, em obras produzidas por autores locais. Desse modo, os significados construídos a partir da primeira análise serão ampliados e transformados, permitindo que se perceba como a contingência e a singularidade dos encontros sugerem, também, sua gramaticalidade na perspectiva de um repertório cultural específico.

\section{DONA MARIA ELVIRA E A MÃE DO J ARRO}

Caso se tome a citação de Deleuze (1987), referente à obra de Proust, em que os signos são vistos como objetos de um aprendizado temporal, um dos signos que se coloca para o presente trabalho é Dona Maria Elvira. Uma mulher com quem estive uma única vez, por algumas poucas horas.

Encontrei-me com Dona Maria Elvira numa venda. Ela entrou e logo agitou o estabelecimento. Alguém perguntou por que estava tão alegre, se já tinha bebido uma pinguinha. Travou-se uma conversa entre ela, o dono da venda e um outro velho que já estava lá. Ela muito alegre, dava gargalhadas, mostrando um sorriso sem dentes e velhice sem idade.

‘Quantos anos a senhora tem, D. Maria? ... não sei... quando eu nasci, só vi água... Lá onde eu moro é uma boniteza... Como chama lá, D. Maria? Chama Feio eh, eh, eh, feio que é bonito... Como é o nome da senhora? Eu tenho dois nomes, Maria e Ervira... Tem duas de eu... uma tá aqui, a outra tá lá, lá na casa fazendo as coisas... a outra não deixa você pitar lá não...'

Ao pensar-se no encontro, buscando uma seqüência, pode-se considerá-lo como o primeiro momento, o início da seqüência. Primeiro, porque foi o início da interação com D. Maria Elvira, fato que delimita o acontecimento como um todo. Segundo, porque também esse momento coloca algumas das questões-chave em torno de seu "fazer/dizer". Dos elementos apresentados, pode-se chamar a atenção sobre alguns deles. Primeiro, o contexto espacial - uma venda, em um pequeno distrito do Noroeste Mineiro, durante a manhã. Os participantes do encontro: o dono do estabelecimento, um senhor, D. Maria, e uma estranha e visitante, no caso a narradora. Como terceiro elemento, a comunicação que se trava, por suposto, as mensagens produzidas em torno de uma das personagens.

Esses elementos colocam imediatamente duas questões interligadas: 1) a "self-characterization" (Crapanzano 1992) de/sobre Dona Maria Elvira e sua fala e 2) as mensagens que produziu a partir dos diálogos travados. 
Que se faça, por ora, a retomada de alguns pontos. A entrada efusiva de D. Maria no estabelecimento, os comentários sobre sua alegria e sobre a pinga, feitos por sujeitos a indicarem familiaridade, mostram-se como índices da embriaguez. Somando-se a isso, a conversa com ela traz uma espécie de desconexão ou deslizamentos. A nenhuma das perguntas ela oferece respostas seguramente referenciais. À pergunta sobre a idade - a velhice , ela fala do tempo do nascimento, de sua visão, água; e do lugar onde vive, belo. À pergunta sobre o nome do lugar, ela diz que é Feio, e faz um trocadilho com a beleza. A pergunta sobre o nome, ela responde, trazendo dois nomes. E, quando perguntada sobre seu nome ela oferece não só dois nomes, mas a visão de uma outra dela mesma, que está lá na casa fazendo as coisas.

O termo "self-characterization", a partir de Crapanzano, refere-se ao processo de constituição do "self", por uma dinâmica estabelecida entre "self", "other" e linguagem. Nesse movimento reflexivo e circular cria-se a ilusão de sujeitos estáveis, autônomos e objetificáveis, passíveis de tipificações e caracterizações assentadas em uma ideologia da referencialidade. Um dos exemplos usados por Crapanzano para ilustrar o papel da linguagem², como terceiro elemento desse processo, volta-se à utilização de pronomes pessoais, particularmente o da primeira pessoa, observando-se a relação entre o caráter indéxico-referencial e o potencial anafórico. A possibilidade de identificação e determinação pragmática das posições dos sujeitos é construída dentro dos limites da linguagem, pelos gêneros e convenções comunicacionais que mascaram a oscilação entre o aspecto semântico-referencial e os aspectos pragmáticos das transações verbais.

Desse ponto de vista, D. Maria suplanta a potencialidade anafórica dos pronomes. Seu nome próprio - que, segundo Bourdieu (1986), é o mais evidente tipo de institucionalização e totalização do eu, que garante a identidade do indivíduo - não aponta nem para a indexicalidade nem para a referencialidade que se quer absoluta. Ele(s) não mascara $(m)$ "eus" circunstanciais, mas antes explicita( $m$ ) descontinuidade(s) entre eles.

Relacionando esses dados à sua fala, é interessante ver o que J akobson (s/d) pode fornecer a esse respeito. A partir de sua análise sobre a afasia, são descritas duas operações lingüísticas básicas: a da seleção e a da combinação. Em um caso, o processo enfatizado é o da substituição que, por sua vez, associa-se ao polo metafórico. No segundo caso, a ênfase é dada à combinação e às relações de contigüidade entre as unidades lingüísticas, apontando para a utilização da metonímia.

Retomando a fala de D. Maria Elvira, pode-se perceber que as respostas às perguntas colocadas reforçam a contigüidade, a ênfase no contexto lingüístico: quantos anos/ quando eu nasci/ onde eu moro é uma boniteza/ Feio que é bonito. A respeito do desdobramento do nome, o próprio J akobson analisa um caso, o do escritor russo Gleb Ivanovitc Upensky, em que a mesma situação ocorre: para o romancista, os dois nomes (Gleb e Ivanovitc) são associados a dois seres separados, um ligado às virtudes e outro aos vícios e à figura paterna ${ }^{3}$. 
Andréa Borghi Moreira J acinto

J akobson contrapõe esse fato à obra e ao estilo do escritor, apontando-o como um exemplo da desordem da similaridade, que se liga por sua vez à tendência para a metonímia. Do ponto de vista da "self-characterization" e da tipificação em processo na interação, estaria Dona Maria embriagada ou seria afásica ?

A ação naquele contexto espacial, entretanto, não terminou por aqui.

Durante a conversa, D. Maria pediu ao dono da venda que Ihe arranjasse um pouco de açúcar, dado. A mim, pediu que lhe arranjasse um pouco de café. A conversa prosseguiu até que, em algum momento, ela começou a falar da mulher que morava lá, junto dela.

'A mulher tem os filhos; ela não come, não bebe, não dorme, ninguém vê, mas ela vive lá com seus filhos e os anjinhos.... Os anjinhos cantam assim, quando chega a noite: mãezinha tira eu, mãezinha tira eu...'

Os olhos de D. Maria ficaram cheios de água; ela disse da tristeza da canção, que lhe dava vontade de chorar... e gargalha.

Falei sobre mim, que havia ido ali conhecer a Serra das Araras, já havia conhecido o rio Catarina, já haviam me falado também do Feio, da ponte branca do Feio - principal fonte de abastecimento de água da Vila. Disse que queria ir até lá conhecê-lo.

Dona Maria disse então que eu fosse junto com ela, que morava lá no Feio. Que eu fosse conhecer a casa dela, e a mulher e os filhos da mulher, que cantava de noite e que ninguém via....

Há vários elementos neste momento que merecem ênfase. Um deles é sua ação na 'venda', para obter sua 'feira'. O outro, sua fala, sobre a mulher que junto dela morava, que tinha filhos, anjos, que ninguém via. Um terceiro, a partir do interesse demonstrado em conhecer o rio Feio, seu convite e a possibilidade de conhecer essa outra mulher. Esse momento da seqüência desdobra, portanto, outras questões.

Em relação a "self-characterization" e às tipificações, se o primeiro momento sugeriu embriaguez e talvez loucura, agora há também um ação concreta a indicar uma agência, um auto-monitoramento reflexivo (Giddens 1984). Dona Maria Elvira, entre seus gracejos, faz a feira e garante alguns dos itens da cesta básica. Sua fala porém, sobre a mulher que mora junto dela, novamente propõe a quebra de qualquer referencialidade e reforça o índice da loucura. O terceiro elemento, proposta e convite, é também aposta. Uma aposta que, de certo modo, Dona Maria Elvira faz sobre o entrelaçamento nas dimensões da ação, do pensamento e da linguagem.

De fato, naquele instante do encontro e na ação comunicativa que se configurava, a aposta colocada por Dona Maria foi a da possibilidade do encontro com o impensável, a mãe dos anjinhos, sua dupla, ou sua loucura. Ou talvez, em relação aos signos de sua mensagem, o nada, que é outra possibilidade da aposta. Algo como o dragão de Sperber (1992)5. Do ponto de vista da narrativa, é o momento da aporia.

Embasando-se nos elementos já dispostos, o próximo momento do encontro traz um novo contexto espacial, não mais a 'venda': 
Dona Maria saiu para a rua, carregando o café e o açúcar e, enquanto caminhava, cantava a canção dos anjinhos, "mãezinha tira eu...". Começou então a apontar para o alto, mostrando quantos anjinhos, olha quantos anjinhos. Apontava os postes de luz, e então os vi: aqueles jarrinhos de vidro que ficam em cima de postes antigos. Muitos anjinhos, que só cantam de noite e choram. Por que eles choram, D. Maria? Pro mundo não acabar....

No caminho, D. Maria parou e entrou num bar, sem se dirigir a mim. Achei que tivesse mudado de idéia e parei mais adiante. Logo, porém, ela veio a minha procura e continuamos. As pessoas da vila pareciam se divertir com a situação e lhe perguntavam para onde levava a moça. Parou no açougue, conseguiu carne, e continuou com suas graças.

Um pouco mais adiante, no caminho para o Feio, surgiu outra mulher, mais baixa ainda que $D$. Maria, que devia ter menos de 1,50m. Era mais jovem, também usava um lenço e roupas gastas. Fazia-se acompanhar de um pequeno menino. J untou-se a nós na caminhada. Soube que era sobrinha de D. Maria Elvira, criada por ela depois da morte da mãe. Era Dona Maria quem a ajudava, que arranjava muitas vezes o 'de comer'. No caminho, queixou-se de dor de cabeça; nada haviam comido naquele dia, ela, seu menino e a menina bebê que estava em casa.

Dona Maria seguia na frente do grupo, e sob o sol forte do quase meio-dia, com sua feira na cabeça, ia cantando, fazendo graça, dando gargalhadas.

Se Dona Maria é signo - no processo de "self-characterization" que se faz em torno dela - nessa seqüência, tanto os índices da embriaguez/ loucura como os outros índices dados por sua ação, indicativos de seu 'estar no mundo' - sua busca pelos mantimentos - são transformados, enfatizados, ampliados. Primeiro, o apontar dos postes e dos pequenos jarros de vidro. Os anjinhos de sua fala ganham materialidade.

Igualmente, a peregrinação continuou entre casas e açougues, revelando a participação de uma série de outros agentes para a efetividade de sua 'feira', e o modo como ela acionou uma rede social. Nesse ínterim, ocorre a entrada de novos personagens, a sobrinha e o menino, sugerindo a importância desse ato para outras pessoas e acrescentando novos elementos à sua caracterização. Ela também é tia, tem o respeito da sobrinha e papel fundamental na sobrevivência do pequeno grupo.

Antes de se aprofundar nesses aspectos, a última seqüência do encontro e a resolução da aposta e aporia:

Depois de cruzarmos o rio, começamos a entrar pelo cerrado e Dona Maria apontou-me a Mãe do J arro: uma grande e reluzente torre de energia elétrica. Caminhamos até a casa, por ela visitada todos os dias, onde vivem os filhos, os anjinhos.

Uma área cercada, com placas avisando do perigo; dentro a torre, transformadores, gerador. Circundamos a cerca, até a sombra de uma árvore próxima, enquanto D. Maria me explicava o que era cada coisa: quem era a mãe, as filhas, os anjinhos, as cabaças onde ficava a água que ia até os anjinhos que viviam na cidade. Dona Maria sabia o que era cada coisa, seus nomes, o que faziam. E ouvia durante a noite o que os seres daquele lugar lhe diziam. Quando chegamos à sombra, continuando sua explicação sobre o lugar, mostrou à sobrinha que o caule da árvore sob cuja copa estávamos, estava cheio de resina; era bom remédio para a menina que estava com tosse. A sobrinha obedeceu e recolheu o remédio. 
Despedimo-nos então da Mãe do J arro e de sua família. No caminho, a sobrinha comentou sobre algum fato ocorrido que havia levado D. Maria Elvira a perder o juízo; desde então ela falava aquelas coisas sobre o lugar, como se fosse encantado, que de nada adiantava explicar-lhe sobre o que realmente era. Antes de chegarmos à casa de D. Maria, sua sobrinha mostrou-me a tapera de sua avó.

Chegamos enfim à casa, feita de barro, madeira e palha de buriti, como quase todas as casas de roça da região. Ela mesma a havia construído, com a ajuda de um irmão, muitos anos antes. A casa era pequena, um pouco torta e eu, do alto dos meus $1,54 \mathrm{~m}$, tive que me curvar para nela entrar. Lá dentro, D. Maria reviu as coisas que havia conseguido em sua feira; deu um pedaço de pão para o menino; dividiu o que tinha, inclusive a carne, com a sobrinha. Ao que disse: nunca a tia a deixara passar fome. Não falamos sobre a outra, que morava ali. Na despedida, pediu à sobrinha que voltasse comigo, para que eu não me perdesse.

A despedida é também finalização das seqüências. Foram indicados, ao longo do texto, quatro momentos demarcados, na temporalidade interna do acontecimento. O limite entre eles foi estabelecido pela mudança de cenários, pela presença/ entrada de outros sujeitos na interação e, particularmente, pelas questões que D. Maria colocou diante de mim. Na primeira seqüência, a questão foi a do desejo de constituir o outro, decifrar talvez (lembrando Deleuze), mas também o de tipificar, classificar, nomear.

O segundo momento é marcado pela intensificação de um dos signos emitidos -(a loucura); pela contraposição de sua ação pragmática (a 'feira'); e, sobretudo, pelo convite de ir até a casa.

O terceiro momento denota três elementos importantes. Um, no cenário público da rua, a repetição do gesto de obtenção da comida, não pela compra, mas por uma oferta dos outros habitantes da vila. Dois, na fala, a incidência repetitiva do signo indéxico da loucura/ embriaguez (os anjinhos); agora, entretanto, dotados de referencialidade: representam a parte de um poste elétrico. Três, a chegada da sobrinha, que localiza D. Maria Elvira como membro de uma pequena unidade de parentesco, revelando-lhe um papel social particular, entre os muitos que, porventura, porte.

A última seqüência ocorre no cenário 'das casas' - da Mãe do J arro e de D. Maria Elvira. No cerrado, próximas ao rio Feio, separadas da pequena área urbana do distrito. Sua ação pragmática e seu papel na sobrevivência do pequeno grupo se intensificam. A Mãe do J arro revela-se em sua primeiridade, é ícone, transformador de alta tensão da rede elétrica. E também, um sistema interpretativo e classificatório, ordenado, hierarquizado e inter-relacionado.

Para mim, enquanto sujeito de interação e personagem da narrativa, a seqüência final sublinhou uma das caracterizações de Dona Maria: seu papel no núcleo familiar e sua ação pragmática e reflexiva dirigida tanto à subsistência quanto à manutenção das interações. Encontrar a torre de energia elétrica - o encontro com a referencialidade - enfraqueceu os índices iniciais da loucura e da embriaguez. No entanto, isso não omite as falas emitidas por outros sujeitos que partilham da cotidianeidade da vida de D. Maria, que dizem de sua perda de juízo e de seu gosto pela bebida. 
Decifrando a Mãe do J arro: uma construção do encontro etnográfico

A proposta do próximo item deste trabalho é interpretar o significado das falas, refazendo a análise do acontecimento, a partir de um contexto situacional ${ }^{6}$.

\section{DONA MARIA EUNÍCIA E A CASA DAS LEMBRANÇAS}

O encontro com D. Maria Elvira, acima descrito, ocorreu em 1996, durante uma pesquisa de campo cujo foco espacial era voltado a outras localidades do Noroeste de Minas Gerais ${ }^{7}$. A ida à Serra das Araras (onde vivia D. Maria Elvira), distrito do município de São Francisco, buscava conhecer os espaços tangenciais ao foco central da pesquisa. O encontro na Serra das Araras, por esse ponto de vista, durou poucas horas e foi contingencial, não sendo, tampouco, orientado por questões delimitadas e circunscritas.

Na mesma ocasião, visitei em um dia, a sede do município de São Francisco. Bem diferente da Serra das Araras, distrito rural caracterizado por atividades agropecuárias de subsistência e com baixa densidade populacional, a sede do município congregava índices da urbanidade e da tradição, além de se constituir um dos centros econômicos e políticos regionais. Nesse contexto, houve outro encontro breve e imprevisto, com outras Marias.

Quem me enviou a D. Maria Eunícia foi sua vizinha e amiga, D. Maria Brás, viúva de um ilustre político e escritor da cidade. Havia lhe dito estar interessada na história da cidade. Ao fim do encontro, enviou-me para sua amiga, D. Maria Eunícia, dona de memória muito boa.

Dona Maria Eunícia estava em sua grande, antiga e bonita casa, no centro de São Francisco. Sentada ao lado de uma janela, bordava e tinha a companhia de outra senhora, que logo nos deixou. Foi acolhedora e serena. Contou então que, desde os oito meses de idade vivia na mesma casa - oitenta e seis anos naquela casa, que antes fora de seus avós. O avô era português e a avó dali mesmo, da região. Sempre viveu em São Francisco, a não ser quando saiu para estudar em Diamantina, em um internato. Voltava para casa uma vez por ano; viagem longa, de trem. Tornou-se professora.

Falou da casa. Os netos, ela entendia, pediam mudanças, mais conforto como aqueles que tinham na cidade grande em que viviam. Mudanças dentro da casa, mais conforto, ela permitia; só não permitia mudanças na fachada, nas janelas - era a mesma desde seus avós. Durante sua juventude, seus irmãos tiveram que deixar a cidade por razões políticas, eram da oposição. Ela não queria deixar a casa mas, não era certo um moça solteira ficar ali, sozinha. De qualquer forma, seu noivo já pensava em casamento, e isso lhe permitiu, portanto, permanecer na casa. Olhamos fotos e ela falou dos filhos e netos - quase todos vivendo em outras cidades -, da casa, de um filho já falecido. Os filhos e netos ainda Ihe perguntam se não se sente só, naquela casa grande, onde fica às vezes dias sem falar com ninguém. D. Maria Eunícia falou então das muitas lembranças que guarda ali, na casa. E que se uma pessoa tem suas lembranças, ela nunca está em solidão.

De imediato, a contraposição entre os dois relatos e entre a interação com essas Marias, sugere interessantes 
Andréa Borghi Moreira J acinto

relações e oposições. A repetição do nome Maria e nome duplo é uma delas. A faixa etária, as menções à infância e as associações indicadas por cada uma delas, também indicam paralelos. Ou o contraste entre um falar/ dizer, construído dinamicamente, por um itinerário (com Dona Maria Elvira), e entre um deslocamento do narrar a memória, simultâneo ao sentar-se à janela (com Dona Maria Eunícia).

As casas também apontam outra repetição e transformação nos relatos. De um lado, a casa 'encantada" da torre de eletricidade e as taperas. Sobre o último termo, vale uma pequena digressão. Tapera, nesse contexto, refere-se tanto às casas de roça da região, feitas de buriti e barro (como a de D. Maria Elvira), quanto ao local e fragmentos da antiga morada/casa. Na última seqüência do encontro na Serra das Araras, a "sobrinha" mostra a tapera de sua avó. Para um olhar estrangeiro como o meu, tudo o que via era terra, restos de madeira, arbustos. Para o olhar nativo, signo da antiga morada. Contrastando com tal sutileza e entrelaçamento com o meio ambiente ${ }^{8}$, está a casa de D. Maria Eunícia, signo do passado estável, sólido e inscrito nas ruas da cidade.

Se esses elementos e relações sugeridas indicam, sobretudo, distanciamento e oposição entre essas mulheres e seus mundos, há outros materiais (e narrativas) que podem revelar ligações e interdependências. Refere-se, aqui, à literatura produzida por escritores do Noroeste/ Norte de Minas Gerais, particularmente a de caráter histórico-memorialista.

\section{NAS LETRAS, REENCONTRANDO MARIAS}

Entre a produção literária produzida no Norte e Noroeste de Minas Gerais, as obras de caráter histórico-memorialista são talvez as mais recorrentes. Guardando suas particularidades, é possível encontrarem-se certos padrões em seus temas ou escolhas narrativas. Duas obras podem exemplificar alguns desses padrões que, por sua vez, iluminam algumas das questões tratadas até o momento.

Brasiliano Braz (1977), autor de São Francisco nos Caminhos da História é um deles, e o livro em questão é obra paradigmática para outros autores, não só de Minas Gerais, mas também de Goiás. De fato, Brazé indiretamente mencionado no segundo encontro relatado, o "ilustre político e escritor da cidade", esposo de D. Maria Braz que me levou à D. Maria Eunícia. O autor escreve com a perspectiva de homem da região, letrado e com passado político que, já em 1937, exerceu pela primeira vez o cargo de prefeito. O corpo principal de sua obra é dividido em três períodos, a “história antiga”, "história média”, e "história contemporânea” até o ano de 1976. O fio condutor é especialmente o da política local. Entretanto, num padrão reconhecível entre outras obras do gênero, é impressionante a capacidade do autor em inter-relacionar, através do foco no município, a história local, a nacional 
e o que possa se chamar "história geral". Seja para falar da fundação do território São Francisco - quando o leitor é apresentado a Pizarro e Cortês, às lutas entre Espanha e Portugal ou à "Bandeira Espinoza", em 1531; seja para trazer vínculos entre a história política local e as dimensões políticas estaduais e nacionais.

Outra obra relevante para a discussão é Saga - Hunay de hontem, Unaí de hoje, de Maria Torres Gonçalves (1990), sobre o atual município de Unaí. A autora também entrelaça diferentes escalas espaciais e temporais na história do município e, como Braz, escreve de uma posição "pública" consolidada - foi professora, tendo atuado como diretora de escolas no município. Se Braz revela um enfoque e interesse predominantemente político, o de Gonçalves é sobretudo afetivo e religioso. O livro apresenta em seu índice quase 100 entradas, indicando assuntos que passam do "histórico do município", pela "descoberta das Terras Brasileiras", por referências às primeiras fazendas, às famílias e casas, às igrejas e bispos, médicos ou "figuras populares", instituições ou órgãos públicos.

Mormente na primeira parte do livro, podem-se notar dois momentos referenciais para o restante da obra. Primeiro, o que pode ser caracterizado como definição do território e da maioria dos cenários que serão posteriormente apresentados. Segundo, a apresentação de personagens que poderiam ser caracterizados como protagonistas da história do município: "As Primeiras Famílias", reunindo os que se tornaram médicos, políticos, professores e outros ilustres. Subseqüente a esse item, outro conjunto de personagens é apresentado: "Antigas e Atuais Figuras Populares".

Em outro momento ( acinto 2001), inspirada pela teoria da prática - sobretudo por Goffman e Giddens -, procurei analisar como essas obras representam e fornecem dados sobre a "ordem interacional". O principal material para essa análise é a infinidade de pequenos relatos sobre os mais variados personagens do município, caracterizando o que poderia ser descrito como situações de seu cotidiano.

Acompanhando alguns desses relatos, puderam-se perceber várias situações que colocavam juntas diferentes categorias sociais ou papéis sociais ${ }^{9}$, em cenários específicos, e que sugeriram também um modelo de interação social: a interação marcada por um tom festivo e que não faz 'discriminação de classe'. Ideal, entretanto, recorrentemente associado a uma direção da interação. No caso, aquela que parte dos cidadãos de prestígio, das famílias tradicionais, dos fazendeiros fortes e políticos influentes. Na descrição dessas pessoas e de seus papéis, Gonçalves geralmente as qualifica, partindo de suas lembranças ou de relatos de terceiros, relevando-Ihes a bondade, a generosidade, o trabalho e a boa vontade para com os 'humildes'.

Esse modelo se complementa com a descrição de outros personagens: aqueles que não pertencem às boas famílias, não ocupam posições de prestígio e que são apresentados como "figuras populares - tipos de rua", "tipos populares". Nesse caso, são pessoas, em geral, apresentadas por um primeiro nome ou apelido ${ }^{10}$. Em ambas as obras citadas, 'tipos populares' lembrados como "merecedores de respeito" e por manifestações de 
afeto são, na maioria, qualificados como bons trabalhadores. Outros dessa categoria são aqueles que inspiram pena, curiosidade, temor ou desprezo: os "doidos mansos" e deficientes físicos. Entre os modelos de interação que tais relatos sugeriram, conforme apontado, é recorrente aquele que destaca a "boa vontade para com os humildes" e a centralidade no valor da "boa pessoa"11 - o cuidado de pessoas de "melhor posição" para com os "tipos populares".

Em ambas as obras, complementando os relatos sobre os ilustres e membros das grandes famílias, os tipos populares são também personagens da narrativa do município. Eles fazem parte da vida do lugar e são também suas pessoas, havendo uma inclusão reconhecida. Entretanto, os relatos das situações que descrevem tais modelo e ideal não omitem a hierarquização e a direção estabelecidas nas interações: para alguns há história, para outros há estórias ${ }^{12}$.

Retomando os encontros com as Marias, a partir da análise dessa literatura, as oposições indicadas entre suas caracterizações, falas/ações e outros elementos são re-significadas.

Por exemplo, a tipificação de D. Maria Elvira e o contraste estabelecido entre seu fazer/dizer: entre loucura/ embriaguez de um lado e, de outro, sua ação para a obtenção de mantimentos e subsistência da família, seu papel como provedora. Tendo como pano de fundo elementos trazidos por aquela literatura, como a descrição de "tipos" sociais e modelos de interação, reconhecidos convencionalmente, que esboçam um contexto situacional - pode-se pensar mesmo na coerência da postura de Dona Maria Elvira do ponto de vista do repertório cultural e da estrutura sócioeconômica do universo onde vive e transita. Nesse sentido, suas falas e sua "self-characterization", de certa forma ressurgem como ato ilocucionário (Austin 1975; Tambiah 1985) - como formulação cujo caráter é convencional, é ato performativo, faz algo por meio das interações estabelecidas entre ela e os outros sujeitos do encontro. Sua performance, bem como a de outros sujeitos, dialoga com a tipificação, com o modelo de interação e as posições e hierarquias sociais, depreendidas da leitura e análise desses livros. Os conteúdos proposicionais da fala de D. Maria Elvira não se contrapõem aos conteúdos no nível do comportamento social (Silverstein 1977, p.129), eles o reiteram. Mesmo o contraste entre os dois encontros, com Maria Elvira e Maria Eunícia, é re-significado, pois eles indicam não dois mundos opostos e desconectados, mas dimensões diferenciadas e inter-relacionadas de um mesmo contexto situacional, e dos papéis e condutas que ele sugere.

Como no trabalho de Santos (1994) sobre a obra de Nelson Rodrigues, em que analisa a representação literária de situações constitutivas da vida cotidiana, também os encontros aqui relatados e analisados apontam para regras e convenções, para configurações de interações sociais: "uma dimensão de ritualização que fundamenta o encontro face-a-face e lhe confere (...) certas características (concernentes a uma estrutura e uma regularidade) tidas como próprias aos rituais" (1994, p. 05). 
Retomar Santos é pertinente também pela contraposição que faz entre Goffman e Crapanzano. O modelo elaborado pelo primeiro - sobre as regras convencionalizadas da ação em situação de co-presença, a definição da situação e dos papéis sociais a partir dessas regras, a importância dos interesses em jogo, a eficácia das atuações, a analogia do teatro - traria também "a imagem de um 'self' objetificável", passível de ser lido e descrito pelos outros. A posição de Crapanzano, de outro modo, revelaria como tal leitura e tipificação construídas pelo "eu" e pelos outros dialogicamente, participa de uma ideologia que mascara o que é processo. Santos conclui, indicando que Goffman centra-se em dimensões essenciais da interação social, do ponto de vista dos atores e Crapanzano, por sua vez, revela e desmascara a ideologia da referencialidade definidora dessas dimensões.

Dona Maria Elvira, poeticamente, entrecruza essas posições. Ela é ícone de uma tipificação e de um modelo de interação, e é índice não só do valor da referencialidade, mas da posição e dos papéis sociais que essa mesma referencialidade ou sua ausência criam.

Para encerrar, é fundamental relembrar dois aspectos que todavia limitam essas leituras. Um deles está nas relações entre o acontecimento do encontro e sua representação por meio da construção narrativa do texto, o que traz alguns condicionantes ${ }^{13}$. A outra limitação liga-se ao fato de a interpretação formulada a partir dos livros tomar uma perspectiva hierárquica, relativa a elites locais, que também participam de uma cultura letrada. Talvez, outros sentidos sejam possíveis se o contexto situacional explorado for outro. Por exemplo, um que entrecruzasse sua temporalidade com a da 'tradição do município', mas não se confundisse com ele, como é, em geral, o caso dos quadros fornecidos pelos livros. Refiro-me às populações rurais dessa região que formulam e acionam outros repertórios culturais, como as chamadas, de modo genérico, de sertaneja ou geralista ${ }^{14}$. A partir de uma perspectiva como essa, acredita-se, o signo 'Dona Maria Elvira' levaria a diferentes perguntas e aprendizados, em que talvez, ela pudesse investir-se de novos papéis ou reinventar a 'Mãe do J arro'. Entretanto, tais questões são conjecturas, dependentes de outras pesquisas e, certamente, novos acasos...

Andréa Borghi M oreira Jacinto é mestre em Antropologia Social pela UNICAM P, doutora em Antropologia Social pela UnB e professora da Universidade Estadual do 


\section{NOTAS}

1 Uma primeira versão desse trabalho surgiu em 1996, no contexto de um curso oferecido pelo Programa de Pós-Graduação em Antropologia Social (Unicamp), "Itinerários e Tramas: histórias de vida e narrativas", ministrado pela Profa. Maria Suely Kofes. Naquela ocasião, a reflexão considerou, sobretudo, a questão da legitimidade da construção narrativa, ao tentar representar um acontecimento e transformálo em dado etnográfico. A presente versão ganhou contribuições de outro curso, em 2000, oferecido no Programa de Pós-Graduação em Antropologia (UnB) e ministrado pela profa. Mariza Peirano, "Análise Antropológica de Rituais".

2 Cabe, entretanto, apontar que a função do "terceiro", refere-se à linguagem de um ponto de vista ampliado. Segundo o autor, "More abstractly, the function of the Third may be simbolized by such notions as the law, convention, reason, culture, tradition, language and tact' (Crapanzano 1992: 93)

3 Interessante notar que para se referir ao escritor e sua obra, J akobson utiliza-se do terceiro nome Upensky. Certamente, há a convenção de citar autores por seus últimos nomes, mas isso não deixa de sugerir a idéia da criação dos "eus" circunstanciais. J akobson (s.d.:59$60)$.

A utilização do tratamento “Dona” em relação à Maria Elvira também indica uma convenção e um índice de respeito na interação, utilizado por mim. Convém notar entretanto que o tratamento dado nessa região, entre nativos, aos idosos da roça já "sem idade", é muitas vezes o "véio", "véia”. Ainda, segundo o antropólogo J oão Batista de Almeida Costa, em comunicação pessoal, 'véio/velho' é um título de honradez e que não se aplica a qualquer pessoa que é chamada de 'dona' ou 'senhor'.

Aproveito para agradecer a esse último, e também a Walkyria de Campos, as valiosas contribuições críticas que me ofereceram.

4 Pergunta que dá margem à outra: a relação entre embriaguez e afasia e que, infelizmente não tenho condições de responder. Trata-se assim, no presente contexto, de uma pergunta retórica...

5 Sperber (1992), a partir de uma proposta recebida - matar um dragão - discute a questão de "como encarar as crenças aparentemente irracionais?", construindo, ao mesmo tempo, uma crítica ao relativismo.

6 A partir da inspiração em Malinowski, Silverstein (1977) refere-se às situações de fala (speech situations), associadas ao momento da enunciação, à utilização das mensagens e a uma gramaticalidade cultural. Trazendo esses elementos à reflexão sobre a linguagem, Silverstein contrapõe-se à postura de considerar os significados somente a partir de sua função referencial, revelando a construção da função indéxica.

7 À época, a Serra das Araras era distrito do município de São Francisco. A partir de 1997, tornou-se distrito do então emancipado município da Chapada Gaúcha, um dos focos da pesquisa mencionada. Ver J acinto (1998).

8 Ou seja, o contraste aponta para maneiras diferentes de simbolizar o passado e o tempo, associadas a modos distintos de organização social entre o citadino e o camponês/sertanejo. Com a morte ou mudança de seus proprietários, a tapera pode desaparecer aos poucos da paisagem física, mas continua ocupando lugar na paisagem simbólica.

9 O papel social é "definido como a promulgação de direitos e deveres ligados a uma determinada situação social, podemos dizer que um papel social envolverá um ou mais movimentos, e que cada um destes pode ser representado pelos atos numa série de oportunidades para o mesmo tipo público ou para um público formado pelas mesmas pessoas". Goffman (1989: 24).

10 Ao contrário, as pessoas referidas como sendo de famílias tradicionais em geral são apresentadas pelos nomes completos. Contudo, feita a apresentação dessas pessoas, é também comum a utilização de apelidos, indicadores de informalidade, afetividade e proximidade.

11 Chaves (1996), em pesquisa realizada em Buritis, também município do Noroeste Mineiro, analisa as relações políticas do município pela perspectiva de seus fundamentos morais, apontando a centralidade, colocada no valor da pessoa (em contraste com a noção de indivíduo) e a qualificação da "boa pessoa".

12 Não parece descabido pensar os relatos dos tipos populares em oposição à narração dos "grandes fatos do município", correlata àquela entre história/ estória. O prefácio da livro de Braz (1977: 12), escrito por um autor cuja obra é paradigmática desse gênero no Norte/Noroeste de Minas (Hermes de Paula, escritor de Montes Claros/MG) reforça essa questão: "além da política e história, ele conta também estórias de beira de rio, focaliza os tipos populares, narra fatos em excelentes crônicas". 
13 Relacionados a perguntas como: em que medida a narrativa, em sua totalidade, não antecipa as direções da análise do acontecimento? E há também outras tipificações existentes e a utilização freqüente do discurso indireto livre, recurso utilizado para contornar o problema de falas 'guardadas' não por um registro material que preservasse sua integridade, mas, sobretudo, por fragmentos do diário de campo e pela suspeitável memória da pesquisadora. Não me parece que tais aspectos invalidem a análise desenvolvida ou a riqueza dos encontros descritos. Devem, na verdade, merecer em outra ocasião uma reflexão mais centrada sobre as relações entre as noções de 'acontecimento', 'evento' e 'narrativa'.

14 Notando que essas também são denominações genéricas. Aqui, são utilizadas para indicar populações que habitam regiões rurais e fronteiriças entre sul da Bahia, Norte/ Noroeste de Minas Gerais e sudoeste de Goiás, e que sugerem modos de organização social e ocupação espacial particulares, bem como tradições culturais próprias. Entre os trabalhos que apontam para a diversidade sociocultural da região, podem-se citar Costa (2001), J acinto (1998), Costa Silva (1998), entre outros. 
Andréa Borghi Moreira J acinto

\section{BIBLI OGRAFIA}

AUSTIN, J . L. 1975. How to do things with words. Cambridge, Mass.: Harvard University Press.

BOURDIEU, Pierre. 1986. “L'Illusion Biographique” in Actes de la Recherche in Sciences Sociales (62/63).

BRAZ, Brasiliano. 1977. São Francisco nos caminhos da História. Belo Horizonte: Editora Lemi S.A..

COSTA, J oão Batista de Almeida. 2001 “Brejo dos Crioulos e a Sociedade Negra da J aíba. Novas Categorias Sociais e a Visibilização do Invisível na Sociedade Brasíleira" in Pós - Revista Brasiliense de Pós-Graduação em Ciências Sociais, Brasília, n. 05.

COSTA SILVA, René Marc. 1998. Por Onde O Povo Anda... A Construção da Identidade Quilombola dos Negros de Rio das Rãs. Tese de Doutorado. Brasília: UnB.

CHAVES, Christine de Alencar. 1996. Eleições em Buritis: A pessoa política. Série Antropologia. Brasília: Depto. de Antropologia/ UnB. n. 206.

CRAPANZANO, V. 1992. “On self characterization”. In Herme's Dilemma \& Hamlet's desire. On the epistemology of interpretation, Cambridge, Mass.: Harvard University Press., pp. 91-112

. 1994. “Kevin: on the transfer of emotions. American Anthropology, 86. (4), 866-885.

DELEUZE, Gilles.1987. Proust e os Signos. Rio de J aneiro: Forense Universitária.

GIDDENS, Anthony. 1984. A Constituição da Sociedade. São Paulo: Martins Fontes.

GOFFMAN, Erving.1989. A representação do eu na vida cotidiana. Petrópolis: Vozes.

GONÇALVES, Maria Torres. 1990. Saga - Hunay de hontem e Unaí de hoje. Belo Horizonte: Editora Arte Quintal.

J ACINTO, Andréa Borghi. M. 1998. Afluentes de Memória: Itinerários, Taperas e Histórias no Parque Nacional Grande Sertão Veredas. Dissertação de Mestrado. Campinas: UNICAMP.

. 2001."Doidos mansos, Boas Famílias e Eruditos: um diálogo possível entre 'teóricos da prática' e escritores locais do Noroeste de Minas". Trabalho apresentado na IV Reunião de Antropologia do Mercosul. Curitiba. Mimeo.

J AKOBSON, Roman. s/d. “Dois aspectos da linguagem e dois tipo de afasia” in Lingüística e Comunicação. São Paulo: Cultrix, 34-62

PEIRANO, Mariza. 2000. A Análise antropológica de rituais. Série antropologia. Brasília: DAN/ UnB, .n. 210

SANTOS, Ana Flávia M. 1994. Linguagem e construção: considerações sobre a peça “O Beijo no Asfalto: Tragédia carioca em três atos". Trabalho final da disciplina Ritos Sociais, ministrado pela profa. Mariza Peirano/ DAN/UnB.

SILVERSTEIN, M. 1977. "Language as part of culture". In Sol Tax e Leslie G. Freeman (eds) Horizons of anthropology. Chicago: Aldine Publishing Company, pp. 119-131.

SPERBER, Dan. 1992. O Saber dos Antropólogos. Lisboa: Edições 70.

TAMBIAH, S. J . 1985. Culture, Thought and Social Action. Cambridge, Mass.: Harvard University Press . 
Decifrando a Mãe do J arro: uma construção do encontro etnográfico

\section{Decifrando a Mãe do J arro: uma Construção do Encontro Etnográfico}

\section{RESUMO}

O artigo tem como ponto de partida um acontecimento singular: um encontro inusitado, em 1996, durante uma pesquisa de campo na vila da Serra das Araras, noroeste de Minas Gerais, margem esquerda do Rio São Francisco. Recorrendo à inspiração teórica de reflexões sobre análise de rituais e eventos, buscou-se, num primeiro momento, efetuar uma análise interna do acontecimento, desdobrando-se ações que o compõem, considerando-se seus participantes, cenários, interações e comunicações. A partir de questões formuladas pelo encontro (e também pela intriga da narrativa construída), um segundo momento do texto tentará respondê-las pela contraposição a outro encontro de caráter semelhante, e de obras literárias de cunho histórico-memorialista, escritas por autores da região.

PALAVRAS-CHAVE: encontro etnográfico, linguagem, literatura local

\section{Deciphering “Mãe do J arro": a construction of the Ethnographic Encounter}

\section{ABSTRACT}

The article takes as its starting point an unexpected occurrence: an odd encounter during field research in 1996, in the village of Serra das Araras, in the Northeast of the state of Minas Gerais. Inspired by the theoretical study of rituals, the text aims at first to analyze the 'inner frame' of the encounter, separating several actions that compound it, considering its participants, its scenarios, interactions and communications. The questions formulated by the encounter (and also by its narrative), will subsequently be tackled through analysis of another encounter which has occurred during the same research, in similar conditions, and through historical and memorial literature, written by local, regional authors.

KEY WORDS: ethnographic encounter, language, local literature 